\title{
BMJ Open Drug-eluting stents in clinical routine: a 1-year follow-up analysis based on German health insurance administrative data from 2008 to 2014
}

\author{
Elke Jeschke, ${ }^{1}$ Julia Searle, ${ }^{2}$ Christian Günster, ${ }^{1}$ Henning Thomas Baberg, ${ }^{3}$ \\ Peter Dirschedl, ${ }^{4}$ Benny Levenson, ${ }^{5}$ Jürgen Malzahn, ${ }^{6}$ Thomas Mansky, ${ }^{7}$ \\ Martin Möckel $^{2}$
}

To cite: Jeschke E, Searle J, Günster C, et al. Drug-eluting stents in clinical routine: a 1-year follow-up analysis based on German health insurance administrative data from 2008 to 2014. BMJ Open 2017;7:e017460. doi:10.1136/ bmjopen-2017-017460

- Prepublication history for this paper is available online. To view these files please visit the journal online (http://dx.doi org/10.1136/bmjopen-2017017460).

Received 24 April 2017 Revised 1 June 2017 Accepted 13 June 2017

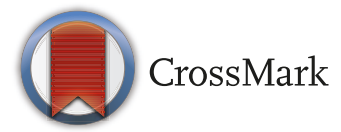

For numbered affiliations see end of article.

Correspondence to

Dr Martin Möckel;

martin.moeckel@charite.de

\section{ABSTRACT}

Objectives To describe the use of drug-eluting stents (DESs) in the largest population of statutory health insurance members in Germany, including newly developed bio-resorbable vascular scaffolds (BVSs), and to evaluate 1-year complication rates of DES as compared with bare metal stents (BMSs) in this cohort.

Design Routine data analysis of statutory health insurance claims data from the years 2008 to 2014. Setting The German healthcare insurance Allgemeine Ortskrankenkasse covers approximately $30 \%$ of the German population and is the largest nationwide provider of statutory healthcare insurance in Germany.

Participants and interventions We included all patients with a claims record for a percutaneous coronary intervention (PCI) with either DES or BMS and additionally, from 2013, BVS. Patients with acute myocardial infarction (AMI) were excluded. Main outcome measure: major adverse cerebrovascular and cardiovascular event (MACCE, defined as mortality, AMI, stroke and transient ischaemic attack), bypass surgery, $\mathrm{PCl}$ and coronary angiography) at 1 year after the intervention.

Results A total of $243581 \mathrm{PCl}$ cases were included (DES excluding BVS: 143765; BVS: 1440; BMS: 98376 ). The 1-year MACCE rate was $7.42 \%$ in the DES subgroup excluding BVS and $11.29 \%$ in the BMS subgroup. The adjusted OR for MACCE was 0.72 (95\% Cl 0.70 to 0.75 ) in patients with DES excluding BVS as compared with patients with BMS. In the BVS group, the proportion of 1-year MACCE was $5.0 \%$.

Conclusion The analyses demonstrate a lower MACCE rate for $\mathrm{PCI}$ with DES. BVSs are used in clinical routine in selected cases and seem to provide a high degree of safety, but data are still sparse.

\section{INTRODUCTION}

Percutaneous coronary interventions (PCIs) are a commonly and increasingly used revascularisation strategy in patients with coronary artery disease (CAD). In Germany, 361377 PCIs were performed in 2014. ${ }^{1}$ Germany is a model region with respect to early availability of new treatment options. For example,
Strengths and limitations of this study

- Data of the largest provider of statutory healthcare insurance in Germany were used, which covers around $30 \%$ of the German population ( 24 million people).

- A total of 243581 percutaneous coronary intervention (PCl) cases were included, and time trends in $\mathrm{PCl}$ utilisation over a 7-year time period were analysed. Data on newly developed BVS are also presented.

- Major adverse cerebrovascular and cardiovascular event, bypass surgery, $\mathrm{PCl}$ and coronary angiography within 1 year after the intervention were analysed.

- Multivariable logistic regression models were used to evaluate the association of $\mathrm{PCI}$ treatment (drugeluting stent excluding bio-resorbable vascular scaffold, bare metal stent) on outcome.

- A subgroup analysis according to the pharmaceutical drug and carrier material was performed.

- The external validity of the data on $\mathrm{PCl}$ utilisation is limited due to slight differences between Allgemeine Ortskrankenkasse insurance members and German patients overall with regard to age and comorbidity profile.

- Data were generated as routine data for billing of claims. Thus, coding inaccuracies cannot be ruled out and important variables may be missing. For example, it was not possible to assess whether a repeat revascularisation was performed in the same vessel as the index $\mathrm{PCl}$.

the mean time from approval to market for new medical drugs is 3.5 months compared with 5.8 months in the Netherlands and 16 months in Spain. ${ }^{2}$

In recent years, case numbers for PCI have been stable on a high level. Still, the utilisation pattern of PCI has changed dramatically over time with a distinct increase of PCIs in patients over the age of 70 years and in patients with comorbidities like diabetes mellitus and chronic kidney disease, as 
compared with 2008. ${ }^{1}$ Additionally, materials used in PCIs have changed. While in the early years uncoated stents made of differing metal alloys (bare metal stents (BMSs)) were used, stents coated with pharmaceutical drugs and polymer (drug-eluting stents (DESs)) are on the rise. DESs were developed to prevent scarring and restenosis of the treated coronary vessel by releasing active agents over a defined period of time. Drugs commonly used in these stents inhibit cell growth, for example, immunosuppressant drugs like Everolimus, Zotarolimus, Sirolimus or the cytostatic drug Paclitaxel-although Paclitaxel is used increasingly less-all in combination with different carrier materials (polymer). The latest development involves bio-resorbable vascular scaffolds (BVSs), which support the vessel over a certain period of time after which they dissolve. The safety and efficacy of BVS have been challenged recently. ${ }^{3}$

DESs have led to a significant reduction of in-stent restenoses (ISR). ${ }^{4-7}$ Still, particularly in the days of first-generation DES in the mid-2000s, there were considerable safety concerns, as a number of studies reported increased rates of late in-stent thromboses compared with BMS. ${ }^{8-12}$ This argument is still being used to favour BMS. For the second-generation DES, these concerns seem not to apply ${ }^{13}$ and current guidelines recommend DES for most patients, although very recent data show that BMS may still have their place (eg, patients with recent bleeding or a need for concomitant anticoagulation therapy). ${ }^{14} 15$ The European Society of Cardiology guidelines mention BVS as a 'promising' option without a clear recommendation. ${ }^{15} \mathrm{~A}$ recent meta-analysis on the use of the 'ABSORB' stent, which is the momentarily most used BVS, resulted in the conclusion that BVS had increased definite/probable scaffold thrombosis (ST) and myocardial infarction (MI) during follow-up compared with DES. ${ }^{16}$

This analysis of German statutory health insurance claims data was performed on the basis of changing conditions and patient populations for PCI treatment, to assess the clinical routine of coronary revascularisation with PCI in Germany. Up until now, the only publication from Germany uses data from the German DES Registry, in which 98 hospitals participated. ${ }^{17}$ We aimed to test the following hypotheses: (a) DESs are the new clinical standard for PCI in Germany and (b) DESs are effective and safe with respect to repeat revascularisation and major adverse cerebrovascular and cardiovascular events (MACCEs) within 1 year after the initial PCI and (c) BVSs are increasingly used in clinical routine with a safe outcome.

\section{METHODS}

Nationwide, anonymous billing data of the statutory health insurance company Allgemeine Ortskrankenkasse (AOK) were used for all 24 million AOK-insured persons in Germany. AOK provides healthcare insurance for approximately $30 \%$ of the German population and is the largest nationwide provider of statutory healthcare insurance in Germany. Every person is allowed to enrol with AOK regardless of age, comorbidity, income or type of employment. Data were derived from billing data for inpatient hospital treatment. They comprise a unique identification number, age, sex, principal diagnosis and other diagnoses, procedures, length of stay, patient survival and insurance status. Diagnoses were coded according to the 10th revision of the International Classification of Diseases (ICD-10). ${ }^{18}$ Procedures were documented using the German version of the International Classification of Procedures in Medicine,$^{19}$ the 'Operationen- und Prozedurenschlüssel' (OPS). Healthcare providers and healthcare insurances jointly issue binding guidelines for coding of diagnoses and procedures in hospital claims. ${ }^{20}$ Hospital claims data in Germany are thoroughly checked against these guidelines and for plausibility by the medical review board of the Social Health Insurance Funds and are returned to hospitals for correction if necessary. Corrections are included in the claims data used in this analysis.

We included all AOK cases from 2008 to 2014 with a claim for inpatient treatment with DES or BMS. Cases were identified by OPS codes (DES excluding BVS: 8-837.m; BVS: 8-83d.0; BMS: 8-837.k). The hospitalisation during which this PCI was performed is referred to as the index hospitalisation.

We excluded all cases with acute myocardial infarction (AMI) and patients with an age below 20 years as well as patients with cardiac surgery or PCI in the year before the index hospitalisation, independent of whether the latter was performed as an inpatient or outpatient treatment, as the outcome of these patients is strongly dependent on other factors than the type of stent.

For the analysis, we formed three subgroups: patients with DES excluding BVS, patients with BVS and patients with BMS treatment. Data for BVS were available only for the years 2013 and 2014.

If patients had multiple stenting during the index hospitalisation with combined DES and BMS stenting, they were assigned to the DES group. This applies to $\mathrm{n}=5.986(2.46 \%)$ of cases.

First, we performed a descriptive analysis on the development of BMS and DES treatment over the predefined 5-year period. Cochrane-Armitage Trend Test was used to analyse trends over these years. In the DES group, we analysed subgroups according to the pharmaceutical drug and carrier material as indicated within the OPS code $8-83 \mathrm{~b}$. We then analysed events during the 1-year follow-up period for the DES and BMS subgroups. Primary endpoint was the 1-year MACCE rate (mortality, AMI, stroke or transient ischaemic attack (TIA); ICD10: I21, I22, I63, G45), which is the proportion of patients who had one or more of these events during the follow-up year. These events are not ordered hierarchically, that is, the MACCE rate is the proportion of patients who had at least one of these events within the follow-up year. In addition, we assessed coronary artery bypass graft CABG surgery 
(OPS: 5-361, 5-362, 5-363), PGI (OPS: 8-837, 8-83d) and coronary angiographies (OPS: 1-275) for different time frames within the 1-year follow-up period. To evaluate the association of PCI treatment (DES excluding BVS versus BMS) with outcomes, we used multivariable logistic regression models. Adjustment was made for age, sex, comorbidities according to the Elixhauser classification, ${ }^{21}$ shock, New York Heart Association (NYHA) class (I versus II, III or IV), left main CAD, multivessel disease (two or three vessels), number of PCIs (one coronary artery versus a minimum of two) at index hospitalisation, AMI and dialysis in the year preceding admission and year of treatment. Comorbidities were defined using the Elixhauser classification. The definition includes 31 acute and chronic comorbidities: congestive heart failure, cardiac arrhythmias, valvular disease, pulmonary circulation disorders, peripheral vascular disease, uncomplicated hypertension, complicated hypertension, uncomplicated diabetes, complicated diabetes (ie, coma, ketoacidosis, vascular disease), renal failure, liver disease, coagulopathy, blood loss anaemia, deficiency anaemia, hypothyroidism, peptic ulcer disease excluding bleeding, chronic obstructive pulmonary disease (COPD), obesity (BMI $\geq 30 \mathrm{~kg} / \mathrm{m}^{2}$ ), weight loss, solid tumour without metastasis, metastatic cancer, lymphoma, fluid and electrolyte disorders, rheumatoid arthritis/collagen vascular diseases, paralysis, other neurological disorders, alcohol abuse, drug abuse, psychoses, depression and AIDS/HIV. Comorbidities were identified using the coding algorithm by Quan $e t$ al based on the ICD-10 coding. ${ }^{22}$ AMI, cardiogenic shock, NYHA class (I versus II, III or IV), left main CAD, multivessel disease (two or three vessels), which are not included in the Elixhauser classification, were also included because they are potential risk factors and differ between the analysed groups $(p<0.005)$. All comorbidities were entered as separate dichotomous variables. Age was used as a continuous variable in the regression analysis. Patients whose AOK insurance ended before the end of the 1-year follow-up period were censored, resulting in differing case numbers for different follow-up periods. All analyses were performed using STATA V.11.2 (StataCorp).

\section{Ethics}

The present study is based on data provided by hospitals for health insurance accounting. The recommendations for good practice in secondary data analysis developed by the German Working Group on the Collection and Use of Secondary Data ${ }^{23}$ were applied in full. This type of analysis requires no formal ethics committee approval.

\section{RESULTS}

The analysis included 243581 cases with PCI, 143765 (59.02\%) in the DES group excluding BVS, 1440 (0.59\%) in the BVS group and 98376 (40.39\%) in the BMS group. In total, $37.0 \%$ of all eligible cases $(n=659067)$ with PCI were included. Cases were excluded according to the exclusion criteria (AMI at the index hospitalisation, cardiac surgery or PCI in the year before the index hospitalisation or age below 20 years).

\section{Study population}

Table 1 shows the basic characteristics of our study population. There were significant differences in patient characteristics between groups (patient age: $\mathrm{p}<0.001$, median test; other variables: $\mathrm{p}<0.05 ; \chi^{2}$ test) in all variables except coronary two-vessel disease $\left(\mathrm{p}=0.408 ; \chi^{2}\right.$ test $)$ and obesity ( $\mathrm{p}=0.054 ; \chi^{2}$ test). Patients in the DES group excluding BVS were 2 years younger than patients in the BMS group (median: 70 vs 72 years). The proportions of patients with prior MI, coronary three-vessel disease, left main CAD and diabetes were higher in the DES group excluding BVS as was the proportion of patients with multiple stenting (number of PCIs $>1$; DES: $18.5 \%$ vs BMS: $6.3 \%)$. In the BMS group, the proportions of patients with heart failure, NYHA class $>1$, cardiac arrhythmia, valvular disease and COPD were higher. The median age of the BVS group was 64 years, and the proportion of patients with concomitant diseases was lower than in the other groups.

The age of patients increased in all groups over time but more prominently in the BMS group (median age in years: DES group excluding BVS 2008: 68; 2014: 71; BMS group 2008: 70; 2014: 75). In 2014, the proportion of patients with an age above 70 years was $53.80 \%$ in the DES group excluding BVS, $69.60 \%$ in the BMS group and $35.96 \%$ in the BVS group. Likewise, the proportion of comorbidities increased over time. This was also most prominent in patients of the BMS group with heart failure, cardiac arrhythmia, valvular diseases and chronic kidney disease. The proportion of patients with cardiac arrhythmia, for example, increased by $8.5 \%$ (2008: $16.0 \%$; 2014: $24.5 \%$ ) in the DES group excluding BVS and by $28.2 \%$ (2008: $24.3 \%$; 2014: $52.5 \%$ ) in the BMS group.

\section{Time trends in percutaneous coronary interventions}

Figure 1 shows the frequency of PCI treatment in AOK patients over time. The proportion of DES increased from $33.6 \%$ in $2008(\mathrm{n}=10843)$ to $84.2 \%$ in $2014(\mathrm{n}=30181)$, including 2.3\% BVS in $2014(\mathrm{n}=856)$. The proportion of BMS decreased accordingly.

Figure 2 shows the development of DES treatment over the predefined 7-year period according to pharmaceutical drug and carrier materials used. The proportion of Everolimus-eluting stents with polymer increased markedly (2008: $25.5 \%$; 2014: $46.4 \%$ ). The same is true for the proportion of Zotarolimus-eluting and Biolimus-eluting stents with polymer (2008: 17.7\%; 2014: $25.5 \%$ and 2008: $5.8 \%$; 2014: $12.4 \%$, respectively). The use of all other stents decreased over this time period, most prominently Paclitaxel-eluting stents with polymer (2008: 29.7\%; 2014: 1.5\%). Very rarely used stents with case numbers below 100 over the 5-year period are not shown. Drugs used in BVS are not sufficiently coded in the data set. 
Table 1 Patient characteristics, for all patients and for the subgroups of patients with DES excluding BVS, BMS and BVS

\begin{tabular}{|c|c|c|c|c|}
\hline & Total & DES excluding BVS & BMS & BVS \\
\hline Number (N) & 243581 & 143765 & 98376 & 1440 \\
\hline Age (median (IQR)) & $71(62-77)$ & $70(61-76)$ & $72(65-78)$ & $64(55-73)$ \\
\hline Female patients (\%) & 32.23 & 31.52 & 33.31 & 28.47 \\
\hline \multicolumn{5}{|c|}{ Diagnoses at the index hospital stay $(\%)^{*}$} \\
\hline \multicolumn{5}{|c|}{ Cardiovascular diseases } \\
\hline Prior Ml & 9.60 & 10.34 & 8.55 & 7.50 \\
\hline Stroke & 0.48 & 0.40 & 0.59 & 0.28 \\
\hline TIA & 0.27 & 0.21 & 0.35 & 0.14 \\
\hline Intracerebral bleeding & 0.04 & 0.03 & 0.06 & 0.00 \\
\hline Congestive heart failure & 26.69 & 25.45 & 28.53 & 25.21 \\
\hline NYHA stage $>1$ & 22.07 & 21.02 & 23.62 & 21.67 \\
\hline Coronary two-vessel disease & 31.54 & 31.63 & 31.39 & 32.15 \\
\hline Coronary three-vessel disease & 37.63 & 40.36 & 33.73 & 30.49 \\
\hline Left main CAD & 3.77 & 4.68 & 2.47 & 1.46 \\
\hline Shock & 0.55 & 0.49 & 0.64 & 0.14 \\
\hline Arterial hypertension & 78.63 & 79.52 & 77.34 & 77.92 \\
\hline Cardiac arrhythmia & 25.30 & 20.48 & 32.44 & 17.29 \\
\hline Valvular disease & 10.11 & 8.75 & 12.14 & 7.43 \\
\hline Peripheral vascular disorders & 11.56 & 11.25 & 12.06 & 8.06 \\
\hline \multicolumn{5}{|l|}{ Other concomitant diseases } \\
\hline Diabetes mellitus & 33.51 & 35.22 & 31.07 & 28.75 \\
\hline COPD & 9.55 & 8.76 & 10.71 & 9.31 \\
\hline CKD & 19.48 & 18.70 & 20.73 & 12.15 \\
\hline ESRD & 3.92 & 3.91 & 3.97 & 2.26 \\
\hline Hypothyroidism & 7.22 & 7.54 & 6.71 & 9.44 \\
\hline Obesity (BMI $\left.\geq 30 \mathrm{~kg} / \mathrm{m}^{2}\right)$ & 12.00 & 12.03 & 11.93 & 13.96 \\
\hline \multicolumn{5}{|l|}{ Interventions at index hospital stay (\%) } \\
\hline $\mathrm{PCl}>1$ coronary artery $\dagger$ & 13.52 & 18.45 & 6.32 & 12.57 \\
\hline Pacemaker & 1.20 & 1.04 & 1.45 & 0.63 \\
\hline ICD implantation & 0.79 & 0.70 & 0.93 & 0.28 \\
\hline Dialysis & 1.75 & 1.59 & 2.00 & 0.69 \\
\hline
\end{tabular}

${ }^{*}$ Other comorbidities according to Elixhauser et al with a frequency $<5 \%$ are not shown (pulmonary circulation disorders, liver disease, blood loss anaemia, deficiency anaemia, peptic ulcer disease excluding bleeding, coagulopathy, weight loss, solid tumour without metastasis, metastatic cancer, lymphoma, rheumatoid arthritis/collagen, paralysis, other neurological disorders, alcohol abuse, drug abuse, psychoses, depression, AIDS/HIV).

†At least two stents in one or more coronary arteries during index hospitalisation.

BMS, bare metal stent; BVS, bio-resorbable vascular scaffold; CKD, chronic kidney disease; COPD, chronic obstructive pulmonary disease; DES, drug-eluting stent; ESRD, end-stage renal disease; ICD, implantable cardioverter defibrillator; MI, myocardial infarction; NYHA, New York Heart Association; TIA, transient ischaemic attack.

\section{MACCE and repeat revascularisation within 1 year}

Table 2 shows event rates for the DES group excluding BVS and BMS group over the whole study period and for the respective years of the study period. In total, the proportion of MACCE during the 1-year period after the index PCI was $7.4 \%$ in the DES group excluding BVS and $11.3 \%$ in the BMS group. Repeat coronary procedures occurred more frequently in the DES group excluding BVS. The proportion of repeat coronary angiographies, for example, was $3.4 \%$ higher in the DES group excluding
BVS (34.5\% as compared with $31.1 \%$ in the BMS group). In the BVS group (data available only for 2013 and 2014), the proportion of 1-year MACCE was $5.0 \%$ and the 1 -year mortality was $2.5 \%$. Repeat coronary procedures within 1 year occurred more frequently in BVS patients (PCI: 25.8\%; repeat coronary angiographies: $39.6 \%$ ).

In the DES group excluding BVS, there was a small increase with respect to 1 -year MACCE over time $(\mathrm{p}<0.001$, trend test). One-year mortality increased (2008: 3.6\%; 2014: $5.1 \%$; $\mathrm{p}<0.001$ ), whereas the proportion of AMI 


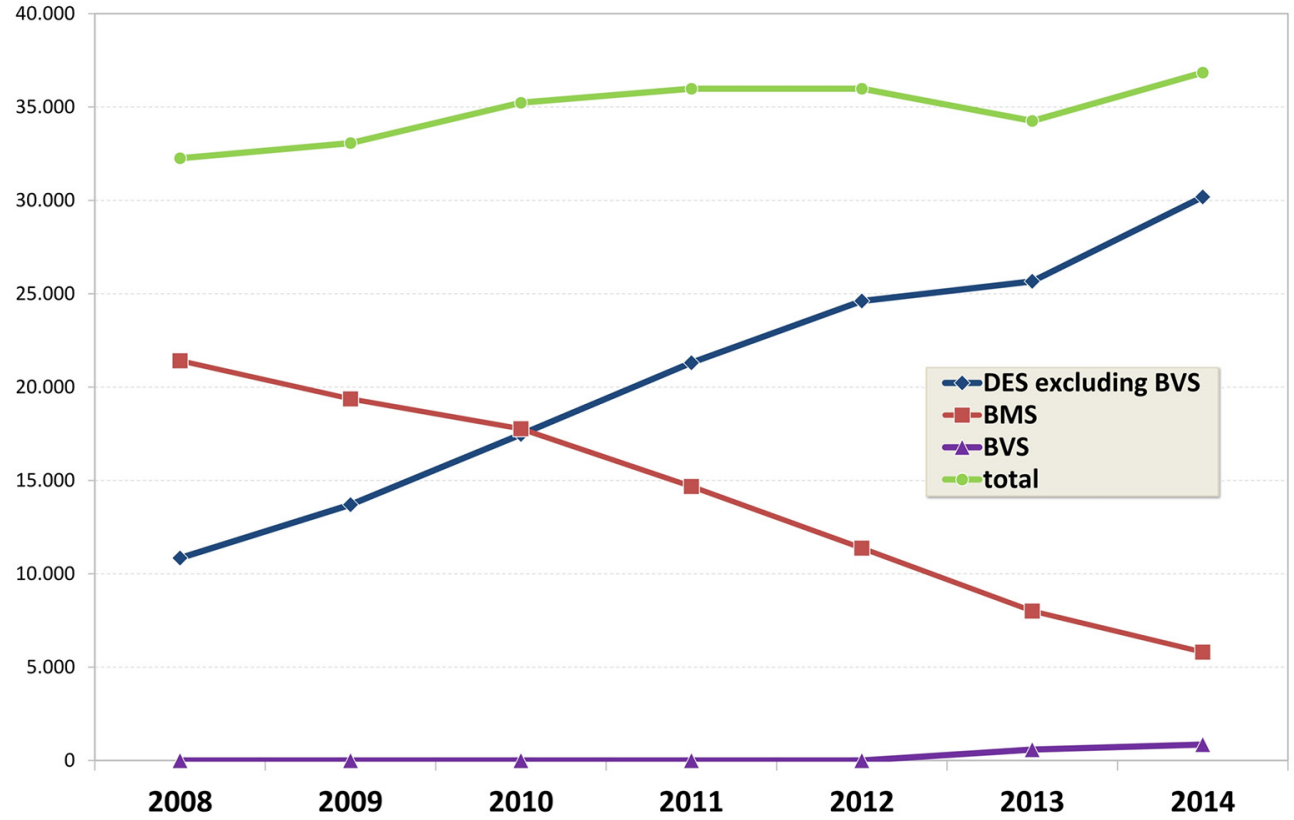

Figure 1 Frequency of drug-eluting stent (DES) and bare metal stent (BMS) including bio-resorbable vascular scaffold (BVS) utilisation over time (2008-2014).

decreased slightly over time (2008: $2.5 \% ; 2014: 2.2 \%$; $\mathrm{p}=0.013)$. In the BMS group, the proportion of 1-year MACCE increased by $5.3 \%$ (2008: 9.6\%; 2012: $14.9 \%$; $\mathrm{p}<0.001)$. This is mostly driven by an increased mortality (2008: 5.3\%; 2014: 10.8\%; $\mathrm{p}<0.001$ ).

Looking at repeat coronary procedures over time, data show a decrease, particularly of coronary angiographies, (DES excluding BVS: 2008: 40.81\%, 2014: 30.69\%; BMS: 2008: 33.66\%, 2014: 26.53\%; p<0.001 for both) but also of CABG surgery (DES excluding BVS: 2008: 1.94\%, 2014: 0.90\%; BMS: 2008: 2.15\%, 2014: 1.28\%, p<0001 for both).
Table 3 shows ORs for DES excluding BVS compared with BMS treatment, risk adjusted for patient characteristics and year of treatment. After risk adjustment, the DES group excluding BVS had a lower risk for 1-year MACCE (OR=0.72; 95\% CI 0.70 to 0.75$)$ and particularly for 1-year mortality ( $\mathrm{OR}=0.70$; CI 0.67 to 0.74$)$, 1-year CABG surgery ( $\mathrm{OR}=0.69$; CI 0.63 to 0.75 ) and repeat PCI within 91-365 days after the index PCI ( $\mathrm{OR}=0.87$; CI 0.81 to 0.93 ). DES group excluding BVS also had a higher risk of PCI within 90 days after the index PCI (OR=1.14; CI 1.07 to 1.21$)$ and of repeat

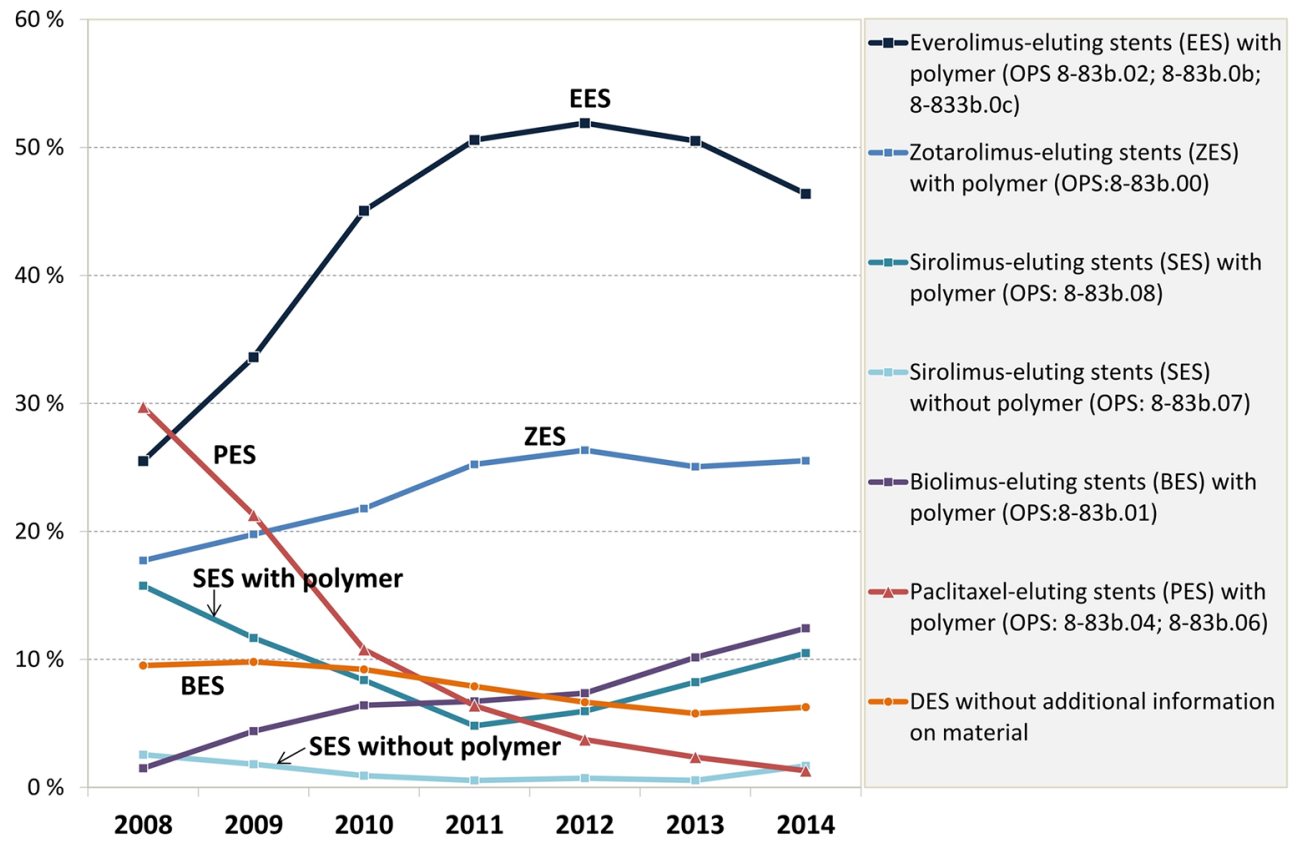

Figure 2 Frequency of the different drug-eluting stent (DES) used over time (2008-2014) according to active drug component and carrier material (groups $>1 \%$ only). Multiple selections were possible due to implantation of different stent types during index procedure. Bio-resorbable vascular scaffolds were not included. OPS 'Operationen- und Prozedurenschlüssel' (OPS) German version of the International Classification of Procedures in Medicine. ${ }^{19}$ 
Table 2 Event rates during the 5-year observation period and during the individual years (claims data of the German local healthcare funds in 2008-2014)

$\begin{array}{llllllll}\text { Total } & 2008 & 2009 & 2010 & 2011 & 2012 & 2013 & 2014 \\ (\%) & (\%) & (\%) & (\%) & (\%) & (\%) & (\%) & (\%)\end{array}$

DES excluding BVS ( $n=143765)$

\begin{tabular}{lrrrrrrrr} 
Mortality during index hospitalisation & 0.57 & 0.41 & 0.42 & 0.50 & 0.44 & 0.56 & 0.60 & 0.83 \\
\hline MACCE (1 year) & 7.42 & 7.04 & 7.60 & 7.21 & 7.01 & 7.17 & 7.53 & 8.28 \\
\hline Mortality & 4.22 & 3.59 & 3.53 & 3.94 & 3.88 & 4.07 & 4.43 & 5.10 \\
AMI & 2.22 & 2.52 & 2.52 & 2.14 & 2.16 & 2.18 & 2.09 & 2.19 \\
\hline Stroke & 1.06 & 1.05 & 1.01 & 1.13 & 1.10 & 0.93 & 1.07 & 1.13 \\
TIA & 0.55 & 0.50 & 0.44 & 0.61 & 0.48 & 0.60 & 0.60 & 0.55 \\
CABG after index hospitalisation (1 year) & 1.20 & 1.94 & 1.44 & 1.52 & 1.22 & 1.04 & 1.02 & 0.90 \\
\hline Of these: within 30 days & 0.09 & 0.11 & 0.08 & 0.11 & 0.10 & 0.11 & 0.09 & 0.08 \\
\hline Of these: within 31-365 days & 1.10 & 1.83 & 1.36 & 1.41 & 1.12 & 0.93 & 0.93 & 0.81 \\
PCl after index hospitalisation (1 year) & 21.40 & 22.50 & 22.86 & 22.46 & 21.80 & 21.09 & 20.65 & 20.32 \\
\hline Of these: within 90 days & 12.59 & 11.62 & 12.18 & 12.37 & 12.75 & 12.91 & 12.75 & 12.76 \\
\hline Of these: within 91-365 days & 8.52 & 10.68 & 10.44 & 9.83 & 8.79 & 7.90 & 7.55 & 7.20 \\
Coronary angiography after index & 34.49 & 40.81 & 39.13 & 37.50 & 35.02 & 33.19 & 32.49 & 30.69
\end{tabular}

hospitalisation (1 year)

$\begin{array}{lrrrrrrrr}\text { BMS ( } \mathrm{n}=98376) & & & & & & & & \\ \text { Mortality during index hospitalisation } & 0.97 & 0.64 & 0.83 & 0.95 & 1.00 & 1.23 & 1.51 & 1.33 \\ \text { MACCE (1 year) } & 11.29 & 9.58 & 10.33 & 11.05 & 11.32 & 12.68 & 14.10 & 14.93 \\ \quad \text { Mortality } & 7.08 & 5.26 & 6.15 & 6.76 & 7.32 & 8.60 & 9.64 & 10.80 \\ \text { AMI } & 3.33 & 3.44 & 3.26 & 3.38 & 3.19 & 3.20 & 3.47 & 3.35 \\ \text { Stroke } & 1.44 & 1.36 & 1.26 & 1.42 & 1.47 & 1.51 & 1.75 & 1.72 \\ \text { TIA } & 0.72 & 0.61 & 0.82 & 0.70 & 0.62 & 0.81 & 0.87 & 0.74 \\ \text { CABG after index hospitalisation (1 year) } & 1.70 & 2.15 & 1.97 & 1.66 & 1.39 & 1.28 & 1.40 & 1.25 \\ \quad \text { Of these: within 30 days } & 0.14 & 0.13 & 0.12 & 0.14 & 0.15 & 0.11 & 0.14 & 0.23 \\ \quad \text { Of these: within 31-365 days } & 1.56 & 2.01 & 1.84 & 1.51 & 1.24 & 1.16 & 1.25 & 1.00 \\ \text { PCl after index hospitalisation (1 year) } & 19.90 & 21.22 & 20.00 & 20.22 & 19.67 & 19.50 & 18.08 & 17.37 \\ \quad \text { Of these: within 90 days } & 10.17 & 10.55 & 10.02 & 10.28 & 10.42 & 10.28 & 9.44 & 8.99 \\ \quad \text { Of these: within 91-365 days } & 9.38 & 10.43 & 9.66 & 9.61 & 8.85 & 8.79 & 8.16 & 7.84 \\ \text { Coronary angiography after index } & 31.14 & 33.66 & 32.21 & 31.84 & 30.26 & 28.71 & 28.29 & 26.53 \\ \text { hospitalisation (1 year) } & & & & & & & & \end{array}$

Patients whose AOK insurance ended before the end of the 1-year follow-up period were censored, resulting in differing case numbers for different follow-up periods. AMI, acute myocardial infarction; BMS, bare metal stent; BVS, bio-resorbable vascular scaffold; CABG, coronary artery bypass graft; DES drug-eluting stent; MACCE, major cerebrovascular and cardiovascular event; PCl, percutaneous coronary intervention; TIA, transient ischaemic attack.

coronary angiography within 1 year $(\mathrm{OR}=1.14$; CI 1.06 to 1.23$)$.

Like DES excluding BVS, ORs for BVS compared with BMS were lower for 1-year MACCE (OR $=0.59 ; 95 \%$ CI 0.46 to 0.74$)$ and for 1 -year mortality $(\mathrm{OR}=0.55$; CI 0.41 to 0.74$)$. The BVS group also had a higher risk of PCI within 90 days after the index PCI (OR=1.83; CI 1.51 to 2.22) and of repeat coronary angiography within 1 year ( $\mathrm{OR}=1.64$; CI 1.33 to 2.02).

\section{Influence of DES stent type}

Table 4 shows the comparison of newer versus first-generation (Paclitaxel) DES. Bio-resorbable stents were excluded as the respective code was only available for 2013 and 2014.

\section{DISCUSSION}

This study assesses the safety of DES in clinical routine in Germany within the first year after index PCI, using statutory health insurance claims data from the largest health insurance in Germany, which covers around 30\% of the German population. In addition, we analysed the consequences of changes in DES utilisation over a 7-year time period. Our data show that the use of DES increased over 
Table 3 Univariable and multivariable logistic regression analysis of the effect of $\mathrm{PCl}$ treatment-DES excluding BVS versus BMS (reference) - on event rates (claims data of the German local healthcare funds in 2008-2014)

\begin{tabular}{|c|c|c|}
\hline & $\begin{array}{l}\text { Adjusted OR* } \\
(95 \% \mathrm{Cl})\end{array}$ & $\begin{array}{l}\text { Crude OR } \\
(95 \% \mathrm{Cl}) \\
\end{array}$ \\
\hline Mortality during index hospitalisation & 0.70 (0.61 to 0.80$)$ & 0.59 (0.53 to 0.66$)$ \\
\hline MACCE (1 year) & $0.72(0.70$ to 0.75$)$ & 0.63 (0.61 to 0.65$)$ \\
\hline Of these: mortality (1 year) & $0.70(0.67$ to 0.74$)$ & 0.58 (0.55 to 0.61$)$ \\
\hline CABG after index hospitalisation (1 year) & $0.69(0.63$ to 0.75$)$ & 0.70 (0.65 to 0.76$)$ \\
\hline Of these: within 30 days & $0.60(0.47$ to 0.76$)$ & 0.68 (0.54 to 0.87$)$ \\
\hline Of these: within $31-365$ days & $0.70(0.64$ to 0.77$)$ & $0.70(0.65$ to 0.77$)$ \\
\hline $\mathrm{PCl}$ after index hospitalisation (1 year) & 0.99 (0.94 to 1.04$)$ & 1.11 (1.04 to 1.15$)$ \\
\hline Of these: within 90 days & $1.14(1.07$ to 1.21$)$ & 1.27 (1.20 to 1.35$)$ \\
\hline Of these: within $91-365$ days & 0.87 (0.81 to 0.93$)$ & 0.90 (0.84 to 0.96$)$ \\
\hline Coronary angiography after index hospitalisation (1 year) & 1.14 (1.06 to 1.23$)$ & $1.16(1.09$ to 1.25$)$ \\
\hline
\end{tabular}

${ }^{*}$ Risk adjustment included age, sex, comorbidities according to the Elixhauser classification, shock, New York Heart Association class (I versus II, III or IV), left main CAD, multivessel disease (two or three vessels), number of PCl (one coronary artery versus a minimum of two) at index hospitalisation, AMI and dialysis in the year preceding admission and year of treatment.

BMS, bare metal stent; BVS, bio-resorbable vascular scaffold; CABG, coronary artery bypass graft; DES, drug-eluting stent; MACCE, major cerebrovascular and cardiovascular event; $\mathrm{PCl}$, percutaneous coronary intervention.

time. One-year MACCEs are consistently less frequent than with BMS over the whole observation period.

\section{Limitations}

Our analyses included AOK patients only. Even though AOK patients form a large population of 24 million insured persons and represent around one-third of all inpatient hospital cases in Germany, external validity of our data on PCI utilisation and MACCE rates is limited due to the fact that the AOK-insured population differs in age and comorbidity profile when compared with other health insurance providers in Germany. ${ }^{24}$ Comparing AOK cases to all German patients with coronary angiography and PCI in 2013, there are slight differences in our study population (female sex: $39.8 \%$ (AOK) vs $35.4 \%$ (Germany); age $\geq 70$ years: $52.7 \%$ (AOK) vs $51.8 \%$ (Germany) $).{ }^{25}$ However, these patient characteristics were controlled for in risk-adjusted analyses.

Table 4 Multivariable logistic regression analyses of the effect of DES type on event rates (claims data of the German local healthcare funds in 2008-2014)

\begin{tabular}{|c|c|c|c|c|c|c|}
\hline & \multirow[b]{2}{*}{ OPS } & \multicolumn{5}{|c|}{ Adjusted OR $(95 \% \mathrm{Cl})^{*}$} \\
\hline & & $\begin{array}{l}\text { Mortality in } \\
\text { hospital }\end{array}$ & $\begin{array}{l}\text { MACCE } \\
\text { (1 year) }\end{array}$ & $\begin{array}{l}\text { Bypass surgery } \\
\text { (1 year) }\end{array}$ & $\begin{array}{l}\mathrm{PCI} \\
\text { (1 year) }\end{array}$ & $\begin{array}{l}\text { Repeat CA } \\
\text { (1 year) }\end{array}$ \\
\hline $\begin{array}{l}\text { Paclitaxel-eluting stents } \\
\text { with polymer }\end{array}$ & $\begin{array}{l}558 \mathrm{~b} .04 \\
558 \mathrm{~b} .06\end{array}$ & $\begin{array}{l}1.00 \\
\text { (reference) }\end{array}$ & $\begin{array}{l}1.00 \\
\text { (reference) }\end{array}$ & $\begin{array}{l}1.00 \\
\text { (reference) }\end{array}$ & $\begin{array}{l}1.00 \\
\text { (reference) }\end{array}$ & $\begin{array}{l}1.00 \\
\text { (reference) }\end{array}$ \\
\hline $\begin{array}{l}\text { Everolimus-eluting stents } \\
\text { with polymer }\end{array}$ & $\begin{array}{l}\text { 883b.02 } \\
\text { 883b.0b } \\
\text { 883b.0c }\end{array}$ & $\begin{array}{l}0.81 \\
(0.61-1.07)\end{array}$ & $\begin{array}{l}0.97 \\
(0.90-1.04)\end{array}$ & $\begin{array}{l}0.81 \\
(0.68-0.95)\end{array}$ & $\begin{array}{l}1.01 \\
(0.96-1.05)\end{array}$ & $\begin{array}{l}0.97 \\
(0.94-1.01)\end{array}$ \\
\hline $\begin{array}{l}\text { Zotarolimus-eluting stents } \\
\text { with polymer }\end{array}$ & $558 b .00$ & $\begin{array}{l}1.10 \\
(0.82-1.46)\end{array}$ & $\begin{array}{l}1.05 \\
(0.97-1.13)\end{array}$ & $\begin{array}{l}0.90 \\
(0.76-1.07)\end{array}$ & $\begin{array}{l}1.00 \\
(0.95-1.04)\end{array}$ & $\begin{array}{l}0.98 \\
(0.94-1.03)\end{array}$ \\
\hline $\begin{array}{l}\text { Sirolimus-eluting stents } \\
\text { with polymer }\end{array}$ & $558 b .08$ & $\begin{array}{l}0.64 \\
(0.43-0.95)\end{array}$ & $\begin{array}{l}0.99 \\
(0.90-1.08)\end{array}$ & $\begin{array}{l}0.93 \\
(0.75-1.14)\end{array}$ & $\begin{array}{l}1.02 \\
(0.96-1.08)\end{array}$ & $\begin{array}{l}1.07 \\
(1.01-1.12)\end{array}$ \\
\hline $\begin{array}{l}\text { Sirolimus-eluting stents } \\
\text { without polymer }\end{array}$ & 558b.07 & $\begin{array}{l}1.09 \\
(0.54-1.11)\end{array}$ & $\begin{array}{l}1.27 \\
(1.06-1.53)\end{array}$ & $\begin{array}{l}1.17 \\
(0.76-1.80)\end{array}$ & $\begin{array}{l}1.36 \\
(1.20-1.54)\end{array}$ & $\begin{array}{l}1.67 \\
(1.50-1.86)\end{array}$ \\
\hline $\begin{array}{l}\text { Biolimus-eluting stents } \\
\text { with polymer }\end{array}$ & $558 b .01$ & $\begin{array}{l}0.76 \\
(0.52-1.11)\end{array}$ & $\begin{array}{l}1.06 \\
(0.96-1.16)\end{array}$ & $\begin{array}{l}0.75 \\
(0.60-0.94)\end{array}$ & $\begin{array}{l}1.04 \\
(0.98-1.10)\end{array}$ & $\begin{array}{l}0.89 \\
(0.85-0.94)\end{array}$ \\
\hline
\end{tabular}

${ }^{*}$ Risk adjusted for age, sex, comorbidities according to Elixhauser classification, shock, New York Heart Association class (I versus II, III or IV), left main disease, multivessel disease (two or three vessels), number of PCl (one coronary artery versus a minimum of two) at index hospitalisation, AMI and dialysis in the year preceding admission. BVSs were not included.

BMS, bare metal stent; BVS, bio-resorbable vascular scaffold; CA, coronary angiography; CABG, coronary artery bypass graft; DES, drugeluting stent; MACCE, major cerebrovascular and cardiovascular event; PCl, percutaneous coronary intervention. 
Data were generated as routine data for billing of claims. Coding inaccuracies cannot be ruled out, and important variables may be missing. For example, we were unable to assess whether a repeat revascularisation was performed in the same vessel as the index PCI. We were also unable to differentiate restenoses and stent thromboses and therefore chose mortality, AMI and repeat coronary procedures as outcomes.

In addition, it has to be noted that due to missing present on admission indexing of AMI, stroke and TIA in claims data, these diagnoses cannot be included under MACCE during the index hospitalisation. The proportion of these diagnoses after PCI has been reported at around $0.3 \% .^{25}$

Finally, routine data do not include detailed clinical information, for example, that needed to check whether indications conformed to the guidelines.

\section{Study population}

Our data show a distinct change in patient characteristics over the study period from 2008 to 2014 . The proportion of patients with an age above 70 years increased, as has been previously reported for PCI patients in Germany (German Heart Report: relative increase by $14.4 \%$ in men and $6.1 \%$ in women). The proportions of patients with diabetes and chronic kidney disease in our data were $34 \%$ and 19\%, respectively (German Heart Report: $27 \%$ and $23 \%$ in 2014). ${ }^{1}$ Patients in the BMS group were slightly older and had more comorbidities such as valvular diseases, atrial fibrillation and coagulopathies, indicating a need for chronic anticoagulation or an increased tendency to bleed. For these patients, treatment seems to follow the current guideline recommendations. ${ }^{15}$ Our data show a significant increase of these comorbidities in the BMS group over time. In the DES group excluding BVS, the proportions of patients with multiple-vessel CAD, left main $\mathrm{CAD}$, previous $\mathrm{AMI}$ and diabetes were higher. In addition, multiple stenting occurred more frequently in this group. These observations confirm study results and recommendations of medical societies on an advantage of DES in patients with an increased risk for restenosis or left main stenosis. ${ }^{26-28}$ BMS treatment is currently recommended for patients with an increased risk of stent thrombosis and in patients with expected complications regarding dual antiplatelet therapy (eg, due to planned elective surgery or anticipated compliance issues). ${ }^{27}$

\section{Time trends in percutaneous coronary interventions}

While the utilisation of PCI has been stabilised on a high level over the past years, the proportion of DES doubled during the study period from $33.6 \%$ in the year 2008 to $84.2 \%$ in 2014, and accordingly, the proportion of BMS was quartered during this period. Case numbers for 2014 confirm a published proportion for Germany of $85.9 \%$ for DES, ${ }^{1}$ although these include patients with AMI. For 2013, an increase of DES utilisation to $79 \%$ was reported. ${ }^{1}$ In our analysis, immunosuppressive drugs with polymer cover $83.1 \%$ of DES in 2014 (Everolimus: $45.5 \%$; Zotarolimus: 23.9\%; Sirolimus: 8.7; Biolimus: $8.0 \%$ ). The increase of DES can be explained by recent reports of clinical trials on their efficacy and safety. ${ }^{26} 2930$

Nevertheless, in the Swedish SCAAR registry (DESs use data available until 2010), the DES rate was a little bit lower with $32 \%$ in the time frame 2009-2010 with same tendency of continuous increase except in 2007-2008 when safety issues were intensively discussed worldwide. ${ }^{31}$

\section{MACCE and repeat revascularisation within 1 year}

The 1-year MACCE rate in our cohort was $7.4 \%$ in the DES group excluding BVS and $11.3 \%$ in the BMS group. In the DES excluding BVS group, the MACCE rate remained nearly stable over time, despite the extended utilisation in elder patients and despite the increase of complex procedures. Considering this, the slight increase in mortality is hardly surprising, especially as some patients who would have been candidates for CABG surgery in earlier days (eg, patients with left main $\mathrm{CAD}$ ) are increasingly treated with PCI. The decreasing proportion of AMI can be explained by the progress of DES development and the use of modern antiplatelet agents like Prasugrel and Ticagrelor. ${ }^{15}$ The proportion of coronary angiographies during the 1-year follow-up decreased markedly over time. This could be explained by an increasing perception of DES as a safe and routinely used treatment option.

Our finding of a distinctly increased 1-year MACCE rate in the BMS group as compared with the DES group has to be discussed considering the higher proportion of patients with an age over 70 years and with comorbidities in the DES group. One-year mortality in the BMS group was twice as high, and the proportion of AMI was higher by a third than in the DES group excluding BVS. In total, the proportion of MACCE in the BMS group increased significantly over the observed time frame.

The adjusted OR for the DES group excluding BVS as compared with the BMS group for 1-year MACCE was 0.72 (95\% CI 0.70 to 0.75 ). Because the practices of German cardiologists have evolved during the study period, we included the year of PCI treatment as a possible confounder in the multivariable regression analysis. However, it has to be considered that DES treatment is not suitable for all patients and that the probability of ISR is higher in the rest of patients' for whom DES treatment is not suitable. Clinical trials recently showed similar risks for DES and BMS in patients with ST-segment elevation myocardial infarction with respect to mortality and repeat AMI but advantages of DES with respect to repeat revascularisation. ${ }^{3233}$ A Canadian registry study, on the other hand, reported a reduced 3-year mortality of the DES group in $2007 .^{6}$

Finally, DES technology has improved over recent years. ${ }^{25} 34$ With new developments and increased safety, further patient groups will benefit from this treatment.

\section{Conclusions}

In summary, our analyses show that DES treatment evolved into the current standard of care over a 7-year observation period. Despite the increased utilisation of DES, 1-year MACCEs are consistently less frequent than 
with BMS over the whole observation period, with a small increase in the last 2 years, indicating broader use. The frequency of repeat coronary diagnostics and procedures decreased over time as DESs are increasingly perceived as safe. BVSs are used in clinical routine in selected cases with high safety, but with a high repeat-coronary angiography rate.

\section{Author affiliations}

${ }^{1}$ Research Institute of the Local Health Care Funds (WId0), Berlin, Germany ${ }^{2}$ Department of Cardiology and Division of Emergency Medicine and Chest Pain Units, Campus Virchow Klinikum and Campus Charité Mitte, Charité Universitätsmedizin Berlin, Berlin, Germany

${ }^{3}$ Department of Cardiology and Nephrology, Helios Klinikum, Berlin-Buch, Berlin, Germany

${ }^{4}$ Medical Service of the Health Funds (MDK) Baden-Württemberg, Lahr, Germany ${ }^{5}$ German Society of Cardiologists in Private Practice (BNK, Bundesverband niedergelassener Kardiologen), München, Germany

${ }^{6}$ Federal Association of the Local Health Care Funds (AOK), Berlin, Germany ${ }^{7}$ Faculty of Economics and Management, Division for Structural Development and Quality Management in Healthcare, Technische Universität Berlin, Berlin, Germany

Contributors EJ, MM and JS have drafted the manuscript; the other authors revised it critically for important intellectual content. All authors contributed to the conception and design of the research. EJ and CG contributed to the acquisition of the data. EJ and MM analysed the data. All authors contributed to the interpretation of the results. All authors have approved of the final version to be published and agreed to be accountable for all aspects of the work in ensuring that questions related to the accuracy or integrity of any part of the work are appropriately investigated and resolved. All authors, external and internal, had full access to all of the data (including statistical reports and tables) in the study and can take responsibility for the integrity of the data and the accuracy of the data analysis.

Competing interests None declared.

Provenance and peer review Not commissioned; externally peer reviewed.

Data sharing statement Raw data and code are accessible at the WId0 under data protection provisions.

Open Access This is an Open Access article distributed in accordance with the Creative Commons Attribution Non Commercial (CC BY-NC 4.0) license, which permits others to distribute, remix, adapt, build upon this work non-commercially, and license their derivative works on different terms, provided the original work is properly cited and the use is non-commercial. See: http://creativecommons.org/ licenses/by-nc/4.0/

(C) Article author(s) (or their employer(s) unless otherwise stated in the text of the article) 2017. All rights reserved. No commercial use is permitted unless otherwise expressly granted.

\section{REFERENCES}

1. Deutsche Herzstifung. Deutscher Herzbericht 2015: Frankfurt, 2015.

2. Medizinische Leistungen in Deutschland gut zugänglich. Dtsch Arztebl 2017;114.

3. Schuetz P, Batschwaroff M, Dusemund F, et al. Effectiveness of a procalcitonin algorithm to guide antibiotic therapy in respiratory tract infections outside of study conditions: a post-study survey. Eur J Clin Microbiol Infect Dis 2010;29:269-77.

4. Moses JW, Leon MB, Popma JJ, et al. Sirolimus-eluting stents versus standard stents in patients with stenosis in a native coronary artery. N Engl J Med 2003;349:1315-23.

5. Stone GW, Ellis SG, Cox DA, et al. A polymer-based, paclitaxeleluting stent in patients with coronary artery disease. $N$ Engl $\mathrm{J} \mathrm{Med}$ 2004;350:221-31.

6. Tu JV, Bowen J, Chiu M, et al. Effectiveness and safety of drugeluting stents in Ontario. N Engl J Med 2007;357:1393-402.

7. Valgimigli M, Sabaté M, Kaiser C, et al. Effects of cobalt-chromium everolimus eluting stents or bare metal stent on fatal and nonfatal cardiovascular events: patient level meta-analysis. BMJ 2014;349:g6427.

8. Daemen J, Wenaweser P, Tsuchida K, et al. Early and late coronary stent thrombosis of sirolimus-eluting and paclitaxel-eluting stents in routine clinical practice: data from a large two-institutional cohort study. Lancet 2007;369:667-78.

9. Joner M, Finn AV, Farb A, et al. Pathology of drug-eluting stents in humans: delayed healing and late thrombotic risk. J Am Coll Cardiol 2006;48:193-202.

10. Lagerqvist B, James SK, Stenestrand U, et al. Long-term outcomes with drug-eluting stents versus bare-metal stents in Sweden. N Engl $J$ Med 2007;356:1009-19.

11. Pfisterer M, Brunner-La Rocca HP, Buser PT, et al. Late clinical events after clopidogrel discontinuation may limit the benefit of drug-eluting stents: an observational study of drug-eluting versus bare-metal stents. J Am Coll Cardiol 2006;48:2584-91.

12. Virmani R, Guagliumi G, Farb A, et al. Localized hypersensitivity and late coronary thrombosis secondary to a sirolimus-eluting stent: should we be cautious? Circulation 2004;109:701-5.

13. Bangalore $\mathrm{S}$, Amoroso N, Fusaro M, et al. Outcomes with various drug-eluting or bare metal stents in patients with ST-segmentelevation myocardial infarction: a mixed treatment comparison analysis of trial level data from 34068 patient-years of follow-up from randomized trials. Circ Cardiovasc Interv 2013;6:378-90.

14. Bønaa KH, Mannsverk J, Wiseth R, et al. Drug-eluting or bare-metal stents for coronary artery disease. $N$ Engl J Med 2016;375:1242-52

15. Windecker S, Kolh P, Alfonso F, et al. 2014 ESC/EACTS Guidelines on myocardial revascularization: The Task Force on Myocardial Revascularization of the European Society of Cardiology (ESC) and the European Association for Cardio-Thoracic Surgery (EACTS) Developed with the special contribution of the European Association of Percutaneous Cardiovascular Interventions (EAPCI). Eur Heart J 2014;35:2541-619.

16. Lipinski MJ, Escarcega RO, Baker NC, et al. Scaffold thrombosis after percutaneous coronary intervention with ABSORB bioresorbable vascular scaffold: a systematic review and metaanalysis. JACC Cardiovasc Interv 2016;9:12-24.

17. Akin I, Nienaber CA, Richardt G, et al. Risk factors for clinical events at 1-year follow-up after drug-eluting stent implantation: results from the prospective multicenter German des.de registry. Clin Res Cardiol 2014;103:363-72.

18. ICD-10. International Statistical Classification of Diseases and Related Health Problems 10th Revision. German Modification. Version 2012. Köln: DIMDI, 2012.

19. ICPM. International classification of procedures in medicine (ICPM). German Modification. Version 2012. KöIn: DIMDI, 2012.

20. German Coding Rules (Deutsche Kodierrichtlinien): InEK GmbH, 2015.

21. Elixhauser A, Steiner C, Harris DR, et al. Comorbidity measures for use with administrative data. Med Care 1998;36:8-27.

22. Quan $\mathrm{H}$, Sundararajan V, Halfon $P$, et al. Coding algorithms for defining comorbidities in ICD-9-CM and ICD-10 administrative data. Med Care 2005;43:1130-9.

23. Arbeitsgruppe Erhebung und Nutzung von Sekundardaten, der Deutschen Gesellschaft für Sozialmedizin und Prävention (DGSMP) und Arbeitsgruppe Epidemiologische Methoden, der Deutschen Gesellschaft für Epidemiologie . . GPS - Gute Praxis Sekundärdatenanalyse: Revision nach grundlegender Überarbeitung Gesundheitswesen 2008;70:54-60.

24. Hoffmann F, Icks A. [Structural differences between health insurance funds and their impact on health services research: results from the Bertelsmann Health-Care Monitor]. Gesundheitswesen 2012;74:291-7.

25. Byrne RA, Serruys PW, Baumbach A, et al. Report of a European Society of Cardiology-European Association of Percutaneous Cardiovascular Interventions task force on the evaluation of coronary stents in Europe: executive summary. Eur Heart $J$ 2015;36:2608-20.

26. Kedhi E, Gomes ME, Lagerqvist B, et al. Clinical impact of secondgeneration everolimus-eluting stent compared with first-generation drug-eluting stents in diabetes mellitus patients: insights from a nationwide coronary intervention register. JACC Cardiovasc Interv 2012;5:1141-9

27. Scheller B, Levenson B, Joner M, et al. Arbeitsgruppe Interventionelle Kardiologie (AGIK) der Deutschen Gesellschaft für kardiologie (DGK). [Medikamente freisetzende Koronarstents und mit medikamenten beschichtete ballonkatheter. Positionspapier der DGK 2011]. Kardiologe 2011;5:411-35.

28. Wang XZ, Xu K, Li Y, et al. Comparison of the efficacy of drugeluting stents versus bare-metal stents for the treatment of left main coronary artery disease. Chin Med J 2015;128:721-6.

29. Deutsche Herzstifung. Deutscher Herzbericht 2013: Frankfurt, 2013. 
30. Serruys PW, Silber S, Garg S, et al. Comparison of zotarolimuseluting and everolimus-eluting coronary stents. N Engl J Med 2010;363:136-46.

31. Fokkema ML, James SK, Albertsson P, et al. Population trends in percutaneous coronary intervention: 20-year results from the SCAAR (Swedish Coronary Angiography and Angioplasty registry). J Am Coll Cardiol 2013;61:1222-30.

32. Cho YK, Hur SH, Park NH, et al. Long-term outcomes of intravascular ultrasound-guided implantation of bare metal stents versus drug-eluting stents in primary percutaneous coronary intervention. Korean J Intern Med 2014;29:66-75.

33. Sethi A, Bahekar A, Bhuriya R, et al. Drug-eluting stents versus bare metal stents in ST elevation myocardial infarction at a follow-up of three years or longer: a meta-analysis of randomized trials. Exp Clin Cardiol 2012;17:169-74.

34. Tada T, Byrne RA, Simunovic I, et al. Risk of stent thrombosis among bare-metal stents, first-generation drug-eluting stents, and secondgeneration drug-eluting stents: results from a registry of 18,334 patients. JACC Cardiovasc Interv 2013;6:1267-74. 